\title{
Dampak Budaya Etis Organisasi Dan Sifat Macheavellian Pada Keputusan Etis Konsultan Pajak Di Provinsi Bali
}

\author{
Naniek Noviari, I Gusti Ngurah Agung Suaryana \\ Universitas Udayana \\ ignasuaryana@yahoo.com
}

\begin{abstract}
The profession of tax consultants is a profession that has ethical decision issues, because these professions are often confronted with conditions of ethical dilemmas, which always threaten the credibility of these professionals, especially the tax consultant profession. There are two views on factors that influence the unethical actions an individual makes. First, views that argue that unethical actions or decision-making are more influenced by the individual's moral character. Second, unethical actions are more influenced by the environment, such as the ethical culture of the organization in which the individual works. Individual characteristic factors that influence decision making include machiavellian behaviour. The research population is all tax consultant in Denpasar City. The study sample was the entire study population. The data used is the primary data obtained from the survey using the questionnaire instrument. Analyzer used is partial least square. The results of the study found that ethical culture produces ethical decisions when the consultant is confronted with an ethical dilemma. Conversely, the macheavellian behaviour of low levels can lead to ethical decisions.
\end{abstract}

Keywords: ethical decision, macheavellian behaviour

\begin{abstract}
Abstrak
Profesi konsultan pajak merupakan profesi yang penuh dengan masalah keputusan etis, karena profesi-profesi tersebut sering dihadapkan pada kondisi dilema etis, yang senantiasa mengancam kredibilitas dari para profesional tersebut, khususnya profesi konsultan pajak. Ada dua pandangan mengenai faktor-faktor yang mempengaruhi tindakan tidak etis yang dibuat seorang individu. Pertama, pandangan yang berpendapat bahwa tindakan atau pengambilan keputusan tidak etis lebih dipengaruhi oleh karakter moral individu. Kedua, tindakan tidak etis lebih dipengaruhi oleh lingkungan, misalnya budaya etis pada organisasi di mana individu tersebut bekerja. Faktor-faktor karakteristik individu yang mempengaruhi pengambilan keputusan antara lain sifat macheavellian. Populasi penelitian adalah seluruh konsultan pajak di Provinsi Bali. Sampel penelitian adalah seluruh populasi penelitian. Data yang digunakan adalah data primer yang diperoleh dari survey menggunakan instrumen kuesiner. Alat analisis yang digunakan adalah partial least square. Hasil penelitian menemukan budaya etis menghasilkan keputusan etis apabila konsultan dihadapkan pada dilemma etis. Sebaliknya, sifat macheavellian pada tingkat yang rendah dapat menghasilkan keputusan etis.
\end{abstract}

Kata kunci: keputusan etis, konsultan pajak, budaya etis organisasi, sifat marcheavellian.

Diterima: 7 Agustus 2108; Revisi: 2018; Disetujui: 2018 


\section{PENDAHULUAN}

Indonesia memiliki sistem perpajakan dengan kompleksitas yang tinggi baik dari banyaknya jumlah peraturan perpajakan yang berlaku dan pembaruan peraturan yang cukup sering dilakukan dari waktu ke waktu. Hal ini semakin menyulitkan wajib pajak dalam mengikuti perkembangan peraturan pajak dan memenuhi kewajiban perpajakannya (Gargalas dan Lehman, 2010). Alternatif yang seringkali menjadi pilihan bagi wajib pajak adalah dengan menggunakan jasa konsultan pajak yang dapat membantu wajib pajak dalam melaksanakan hak dan memenuhi kewajibannya di bidang perpajakan sesuai dengan peraturan perundang-undangan yang berlaku. Dengan sistem self assesment yang diterapkan di Indonesia cukup menyulitkan wajib pajak dalam menjalankan hal-hal tersebut sehingga wajib pajak membutuhkan pihak lain yang dinilai lebih mengetahui dan memahami secara jelas tata cara pelaksanaan kewajiban perpajakan. Salah satu pihak yang dinilai lebih memahami dan mendalami tata cara pelaksanaan kewajiban perpajakan adalah konsultan pajak.

Erard (1993) menyatakan bahwa konsultan pajak memiliki pengaruh yang cukup besar terhadap kepatuhan perpajakan wajib pajak dikarenakan pengetahuan konsultan pajak atas sistem perpajakan yang lebih dibandingkan wajib pajak sehingga wajib pajak memiliki ekspektasi bahwa dengan menggunakan jasa konsultan pajak maka wajib pajak dapat memenuhi kewajibannya dengan jumlah seminim mungkin.

Fakta ini berbanding terbalik dengan hasil penelitian Shafer dan Simmons (2008) yang menjelaskan bahwa sebagian konsultan pajak telah mengabaikan kepentingan umum demi kepentingan klien dan komersial dengan cara memfasilitasi tindakan-tindakan terkait penggelapan pajak. Terungkapnya kasus mengenai pelanggaran etika konsultan pajak menimbulkan kekhawatiran mengenai kurangnya penerapan terhadap etika konsultan pajak.

Profesi konsultan pajak merupakan profesi yang penuh dengan masalah keputusan etis, karena profesi-profesi tersebut sering dihadapkan pada kondisi dilema etis, yang senantiasa mengancam kredibilitas dari para profesional tersebut, khususnya profesi konsultan pajak. Ada beberapa kasus yang terjadi 
terkait dengan pembuatan keputusan yang tidak etis oleh konsultan pajak di Indonesia, diantaranya keterlibatan konsultan pajak Robertus Santonius dan Hendro Tirtawijaya untuk membantu wajib pajak yang ditanganinya untuk melakukan kecurangan, yang terungkap dalam kasus Gayus Tambunan dan Dhana Widyatmika (Harian Merdeka, 2012). Dilema etis yang dihadapi oleh konsultan pajak menghadapkan konsultan pajak untuk membuat suatu keputusan yang bertentangan dengan prinsip-prinsip profesionalitasnya, dengan imbalan ekonomis yang cukup material di sisi lainnya.

Trevino dan Youngblood (1990) menyatakan bahwa terdapat dua pandangan mengenai faktor-faktor yang mempengaruhi tindakan tidak etis yang dibuat seorang individu. Pertama, pandangan yang berpendapat bahwa tindakan atau pengambilan keputusan tidak etis lebih dipengaruhi oleh karakter moral individu. Kedua, tindakan tidak etis lebih dipengaruhi oleh lingkungan, misalnya budaya etis pada organisasi di mana individu tersebut bekerja. Faktor-faktor karakteristik individu yang mempengaruhi pengambilan keputusan antara lain sifat macheavellian.

Penelitian ini bertujuan untuk meneliti pengaruh budaya etis dan sifat Macheavellian. Shafer dan Simmons (2001) menyatakan bahwa individu yang menganggap bahwa perusahaan tidak memiliki tanggung jawab selain memaksimalkan laba, maka akan cenderung melakukan penghindaran pajak. Selain itu, kecenderungan untuk melakukan penghindaran pajak juga dipengaruhi oleh perilaku manipulatif, atau yang sering disebut dengan sifat Machiavellian. Richmond (2001) menemukan bukti bahwa kepribadian individu mempengaruhi keputusan etis. Richmond menginvestigasi hubungan paham machiavellianisme yang membentuk suatu tipe kepribadian yang disebut machiavellian serta pertimbangan etis dengan kecenderungan perilaku individu dalam menghadapi dilema-dilema etika (perilaku etis). Hasil penelitian ini menunjukkan bahwa semakin tinggi kecenderungan sifat machiavellian seseorang, maka semakin mungkin untuk berperilaku tidak etis dan semakin tinggi level pertimbangan etis seseorang, maka dia akan semakin berperilaku etis. 
Lingkungan kerja menjadi faktor yang mempengaruhi etika individu seseorang. Semakin seringnya pimpinan dan karyawan melakukan aktivitas yang tidak etis bahkan ilegal, maka banyak perusahaan yang mengambil langkah untuk meningkatkan perilaku etis di lingkungan kerja, antara lain dengan menetapkan kode etik (Griffin dan Ebert, 1998). Penelitian mengenai faktor-faktor yang berpengaruh terhadap perilaku etis individu dalam pengambilan keputusan telah dilakukan oleh peneliti-peneliti terdahulu. Ferrel dan Gresham (1985); Hunt dan Vitell (1986; 1991) menggambarkan bahwa budaya etis organisasi berpengaruh terhadap proses etis dalam pengambilan keputusan etis. Faktor individual, seperti sifat Macheavellian ditemukan mempengaruhi keputusan etis Shafer dan Simmons (2001).

Konsep machiavellianisme dibangun untuk memahami kepribadian yang manipulatif, dingin, dan penuh perhitungan (Christie, 1970 dalam Shafer dan Simmons, 2008). Machiavellianisme didefinisikan sebagai "suatu proses Dimana manipulator mendapatkan lebih banyak reward dibandingkan yang dia peroleh ketika tidak melakukan manipulasi, ketika orang lain mendapatkan lebih kecil, minimal dalam jangka pendek" (Christie dan Geis, 1970 dalam Richmond, 2001). Kepribadian Machiavellian selanjutnya dideskripsikan oleh Christie dan Gies (1980) sebagai kepribadian yang kurang mempunyai afeksi dalam hubungan personal, mengabaikan moralitas konvensional, dan memperlihatkan komitmen ideologi yang rendah. Kepribadian machiavellian mempunyai kecenderungan untuk memanipulasi orang lain, sangat rendah penghargaannya pada orang lain. Adapun indikator-indikator yang dapat mempengaruhi sifat machiavellian, yaitu afeksi, ego, manipulatif, dan agresif.

Budaya organisasi pada intinya merupakan sebuah sistem dari nilai-nilai yang bersifat umum. Adapun nilai-nilai personal mulai dikembangkan pada saat awal kehidupan, seperti halnya kepercayaan pada umumnya, tersusun dalam sistem hierarki dengan sifat-sifat yang dapat dijelaskan dan diukur, serta konsekuensi-konsekuensi perilaku yang dapat diamati (Douglas et.al., 2001). Sistem nilai umum yang dijelaskan oleh Ouchi (1980). Nilai-nilai tersebut merupakan inti dari budaya organisasi yang tercermin dalam praktek organisasi. 
Persepsi terhadap budaya organisasi didasarkan pada kondisi-kondisi yang dialami seseorang dalam organisasinya, seperti penghargaan, dukungan, dan perilaku yang diharapkan diperoleh di organisasi.

Fogarty (1992) mendefinisikan sosialisasi sebagai proses dimana individuindividu dibentuk oleh lingkungan sosial dimana mereka menjadi anggota yang utuh. Sosialisasi mempunyai peranan penting dalam organisasi profesional, seperti konsultan pajak, dimana baik perilaku karyawan maupun output kinerja yang diharapkan dapat terukur. Organisasi ini harus bergantung pada clan control (Ouchi, 1980) atau operasi dari nilai umum yang kuat untuk mengendalikan sifat oportunis dan ketidakefisienan yang disebabkan oleh ketidaksesuaian antara tujuan individu dan organisasi.

Dalam perekrutan dan seleksi, aparatur baru tidak sepenuhnya diindoktrinasi dalam budaya organisasi. Oleh karena itu suatu organisasi berniat membantu aparatur baru untuk menyesuaikan diri dengan budayanya. Proses penyesuaian ini disebut sosialisasi (Robbins, 1996). Tahap sosialisasi yang paling kritis adalah pada saat memasuki organisasi itu. Inilah pada saat organisasi itu berupaya membentuk orang luar itu menjadi seorang aparatur yang baik.

Sosialisasi dapat dikonsepkan sebagai suatu proses yang terdiri atas tiga tahap; prakedatangan, perjumpaan dan metamorfosis. Tahap prakedatangan meliputi semua pembelajaran yang terjadi sebelum seorang anggota bergabung dengan organisasi itu. Dalam tahap perjumpaan, aparatur baru tersebut akan melihat seperti apakah organisasi itu sebenarnya dan kemungkinan bahwa harapan dan kenyataan dapat berbeda. Dalam tahap metamorfosis ini dimana seorang aparatur baru menyesuaikan diri pada nilai dan norma kelompok kerjanya. Ponemon (1990) menyarankan bahwa sosialisasi di profesi akuntansi pada kenyataanya berawal dari sejak masa kuliah, dimana mereka ditanamkan perilaku dan nilai-nilai profesional. Ponemon (1990) mengkonfirmasikan adanya mekanisme seleksi dan sosialisasi untuk mengontrol alasan etis pada akuntan publik. 
Keputusan etis (ethical decision) adalah sebuah keputusan yang baik secara moral maupun legal dapat diterima oleh masyarakat luas. Ada 3 unsur utama dalam pembuatan keputusan etis, yaitu pertama, moral issue, menyatakan seberapa jauh ketika seseorang melakukan tindakan, jika dia secara bebas melakukan itu, maka akan mengakibatkan kerugian (harm) atau keuntungan (benefit) bagi orang lain. Kedua adalah moral agent, yaitu seseorang yang membuat keputusan moral (moral decision). Dan yang ketiga adalah keputusan etis (ethical decision) itu sendiri, yaitu sebuah keputusan yang secara legal dan moral dapat diterima oleh masyarakat luas.

Sikap seseorang terhadap setiap tindakan, bersama dengan norma subyektifnya terhadap tindakan tersebut, akan mempengaruhi pertimbangan individual atas setiap pilihan tindakan. Pada tindakan-tindakan tertentu, seseorang akan memilih solusi terbaik atas setiap masalah yang muncul. Dalam teori ini, sikap (attitude) adalah hasil dari keyakinan dan nilai atas suatu tindakan, sedangkan norma subyektif (subjective norms) merupakan keyakinan seseorang terhadap tindakan-tindakan yang mungkin diambil oleh orang lain. Tindakan tersebut terbentuk setidaknya memenuhi kedua kriteria, baik attitude maupun subjective norms. Oleh karena itu, setiap pertimbangan pengambilan keputusan dipengaruhi oleh sikap individual dan norma subyektif yang dimilikinya.

Skala Machiavellian menjadi proksi perilaku moral yang mempengaruhi perilaku pembuatan keputusan etis. Sehingga diekspektasikan bahwa individu dengan sifat Machiavelian tinggi akan lebih mungkin melakukan tindakan yang tidak etis dibandingkan individu dengan sifat Machiavellian rendah. Christie dan Geis (1970) seperti dikutip oleh Purnamasari dan Chrismastuti (2006) menyatakan bahwa Machiavellian merupakan sebuah kepribadian yang antisosial, tidak memperhatikan moralitas konvensional dan mempunyai komitmen ideologis yang rendah. Individu yang memiliki kepribadian Machiavellian yang tinggi melakukan apapun yang diperlukan untuk mencapai tujuannya.

Shafer dan Simmons (2006) menyatakan bahwa seseorang yang cenderung menggunakan taktik manipulatif dan kurang peduli terhadap moral akan terlibat dalam tindakan tidak etis dalam berbagai situasi. Individu yang mendapatkan nilai 
tinggi dalam skala Machiavellian cenderung kurang terpengaruh oleh masalah moral seperti keadilan, dan lebih menyukai untuk "menang". Kepribadian tersebut cenderung melakukan taktik manipulatif kecurangan dalam bisnis serta melakukan tindakan-tindakan tidak etis. Shafer dan Simmons (2006) melakukan penelitian mengenai pengaruh sifat Machiavellian terhadap profesional pajak di Hong Kong, dan menunjukkan hasil bahwa Machiavellian memiliki dampak yang signifikan pada penilaian keputusan etis. Penelitian lain yang menyatakan bahwa Machiavellian memiliki pengaruh yang signifikan terhadap pengambilan keputusan etis dilakukan oleh Singhapakdi (1991). Singhapakdi menyatakan bahwa seorang inidividu yang memiliki nilai Machiavellian tinggi cenderung memiliki norma etika yang lebih rendah. Penelitian Singhapakdi tersebut didukung juga oleh Trevino et al. (1985) dalam Purnamasari (2006), Richmond (2001), Pan dan Sparks (2011), Chrismastuti dan Purnamasari (2004), Tjongari dan Widuri (2014), Adriana et al. (2015), Kusuma et al. (2016) dan Ariestanti et al. (2016) yang menyatakan bahwa skala Machiavellian mempengaruhi perilaku pembuatan keputusan etis. Hal ini mengindikasikan bahwa individu dengan sifat Machiavellian tinggi akan lebih mungkin melakukan tindakan tidak etis dibandingkan dengan individu dengan sifat Machiavellian rendah.

Menurut Douglas et al. (2001) budaya merupakan system nilai yang bersifat umum. Menurut Schein (1985) budaya etis organisasi merupakan standar yang mengatur adaptasi internal dan eksternal sebuah organisasi. Hunt et al. (1989) menyatakan bahwa temuan Alchian (1972) juga mengungkapkan bahwa budaya etis organisasi memiliki pengaruh yang sangat kuat dalam membentuk perilaku dan pertimbangan etis semua orang yang ada dalam perusahaan tersebut. Penelitian Douglas et al. (2001) menemukan pengaruh antara budaya etis organisasi pada pertimbangan etis auditor. Penelitian yang dilakukan Vitell (2006) menunjukan bahwa budaya etis organisasi mempunyai pengaruh pada pertimbangan etis. Noviriantini et al. (2015) menemukan budaya etis organisasi berpengaruh negatif terhadap kecenderungan kecurangan (fraud). Budaya etis 
organisasi terbukti berpengaruh pada sensifitas etis auditor (Falah, 2007; Sutiarsih et al., 2014; Marina et al., 2015; .

\section{METODE}

Populasi dalam penelitian ini adalah konsultan perpajakan dan staf perpajakan yang bekerja di Kantor Konsultan Pajak (KKP) di Bali. Tercatat 85 KKP yang tersebar di Bali berdasarkan data Ikatan Konsultan Pajak Indonesia Cabang Bali. Seluruh populasi menjadi sampel penelitian. Penelitian ini terdapat variabel eksogen dan variabel endogen.

Christie dan Geis (1970) mendefinisikan kepribadian Machiavellian sebagai kepribadian yang kurang mempunyai afeksi dalam hubungan personal, mengabaikan moralitas konvensional, dan memperlihatkan komitmen ideologi yang rendah. Tingkat kecenderungan sifat Machiavellian diukur dengan skala Mach IV yang dikembangkan oleh Christie dan Geis (1970). Skala Mach IV terdiri dari 20 item pertanyaan dengan skala Likert yang akan berisi pertanyaan tentang tingkat setuju dan tidak setuju untuk masing-masing item pertanyaan. Skor 1 (sangat tidak setuju) sampai dengan 5 (sangat setuju). Semakin tinggi skor berarti semakin tinggi tingkat sifat Machiavellian responden.

Budaya etis organisasi adalah pandangan luas tentang persepsi karyawan pada tindakan etis pimpinan yang menaruh perhatian pentingnya etika di perusahaan dan akan memberikan penghargaan ataupun sangsi atas tindakan yang tidak bermoral. Budaya etis organisasi diukur dengan menggunakan 5 item yang dikembangkan oleh Hunt et al. (1989). Setiap item pertanyaan berisi tentang tindakan-tindakan yang dilakukan pimpinan terhadap bawahannya pada tindakan yang etis maupun tidak etis.

Variabel endogen adalah variabel yang dianggap dipengaruhi oleh variabel lain dalam model. Adapun variabel endogen dalam penelitian ini adalah keputusan etis. Pembuatan keputusan tidak terlepas dari keterlibatan etika, karena pertimbangan etis merupakan sebuah kriteria dalam pembuatan keputusan organisasional (Robbins, 2008). Individu dengan standar etika yang tinggi kemungkinan besar tidak terlibat dalam perbuatan tidak etis, bahkan dalam 
organisasi atau situasi di mana terdapat tekanan yang kuat ntuk menyesuaikan diri. Pengukuran variabel keputusan etis menggunakan pertanyaan dari skenario. Pengukuran variabel ini mengacu pada penelitian Shafer dan Simmons (2008) yang menggunakan skenario yang mengandung dilema etis. Responden akan memberikan tanggapan mengenai skenario tersebut, apakah tindakan yang diambil dari situasi dalam skenario tersebut etis atau tidak.

Pengumpulan data dalam penelitian ini dilakukan dengan metode survei, yaitu dengan menyebarkan daftar pertanyaan berupa kuesioner yang akan diisi oleh konsultan pajak di KKP di wilayah Bali. Kuesioner ini terdiri dari dua bagian, yaitu bagian pertama berisi demografi responden, dan bagian kedua merupakan sejumlah kelompok pertanyaan yang telah terstruktur. Kuesioner pada penelitian ini berasal dari penelitian terdahulu, baik yang dilakukan oleh Richmond (2001) maupun Shafer dan Simmons (2008). Sebelum kuesioner diperbanyak, dilakukan pilot test terlebih dahulu. Responden berasal dari mahasiswa yang telah memperoleh mata kuliah Perpajakan 2 atau Praktikum Perpajakan. Jumlah sampel yang digunakan untuk melakukan pilot test adaalah 30 orang mahasiswa. Tujuan dilakukan pilot Test terlebih dahulu adalah untuk menguji validitas dan reliabilitas item-item dalam kuesioner.

Penelitian ini menggunakan alat statistik partial least square (PLS). PLS merupakan metode analisis yang powerful karena dapat diterapkan pada semua skala data, tidak membutuhkan banyak asumsi dan ukuran sampel tidak harus besar. PLS selain dapat digunakan sebagai konfirmasi teori juga dapat digunakan untuk membangun hubungan yang belum ada landasan teorinya atau untuk pengujian proposisi (Ghozali, 2008). Terdapat dua macam indikator dalam pendekatan PLS.

\section{HASIL DAN PEMBAHASAN}

Populasi yang menjadi obyek dalam penelitian ini adalah seluruh konsultan pajak di Kota Denpasar. Jumlah konsultan pajak yang menjadi anggota Ikatan Konsultan Pajak Indonesia Cabang Bali sebesar 85 orang. Sampel yang 
digunakan dalam penelitian ini dipilih dengan metode sampel jenuh, yaitu seluruh populasi penelitian.

Kuesioner yang diberikan kepada 85 responden, namun kuesioner yang dikembalikan sejumlah 75 buah. Semua kuesioner yang dikembalikan pengisiannya lengkap dan memenuhi ketentuan sehingga tidak ada kuesioner yang gugur. Berikut adalah ringkasan pengiriman dan pengembalian kuesioner.

Tabel 1. Ringkasan Pengiriman dan Pengembalian Kuesioner

\begin{tabular}{lc}
\hline Kuesioner & Jumlah \\
\hline Kuesioner Tersebar & 85 \\
Kuesioner Kembali & 75 \\
\hline
\end{tabular}

Sumber: Data diolah, 2017

Karakteristik demografi responden dalam penelitian ini merupakan profil dari 75 responden yang mengisi kuesioner ini. Karakteristik responden ini meliputi jenis kelamin, umur, dan tigkat pendidikan. Berikut adalah Tabel 2. Demografi Responden.

Pada penelitian ini dari 75 responden penelitian, terdapat 60 orang atau $77 \%$ responden laki-laki, sedangkan terdapat 15 orang atau sebesar 23\% responden perempuan. Proporsi konsultan pajak di Kota Denpasar terbesar adalah kelompok umur lebih dari 30 tahun, yaitu sebesar 81\%.

Tabel 2. Demografi Responden

\begin{tabular}{|c|c|c|c|}
\hline 1 & Jenis Kelamin & & \\
\hline & - Pria & & $80 \%$ \\
\hline & - Wanita & 60 Responden & $20 \%$ \\
\hline 2 & Umur & $1[$ Dnannndan & \\
\hline & $<30$ Tahun & 14 Responden & $19 \%$ \\
\hline & > 30 Tahun & 61 Responden & $81 \%$ \\
\hline
\end{tabular}

\section{Sumber: Data Primer Diolah, 2017}

Hasil analisis PLS di dalam penelitian meliputi analisis model pengukuran dan analisis model struktural. Analisis model pengukuran, meliputi analisis validitas dan reliabilitas setiap variabel penelitian. Analisis model struktural meliputi analisis validitas model dan koefisien jalur.

Analisis model pengukuran meliputi pengujian atas validitas reliabilitas 
instrumen (Hartono, 2011). Validitas konstruk menunjukan seberapa baik hasil yang diperoleh dari penggunaan satu pengukuran sesuai dengan teori-teori yang digunakan untuk mendefinisikan konstruk (Hartono, 2011). Pengujian validitas konstruk di dalam penelitian ini, meliputi validitas konvergen dan validitas diskriminasi.

Validitas konvergen berhubungan dengan prinsip bahwa setiap pengukur dari kostruk seharusnya berkorelasi. Validitas konvergen diukur dengan loading faktor (korelasi antara skor komponen dengan skor kontruk). Hasil pengujian validitas konvergen pada Tabel 3 menghasilkan skor outer loading lebih besar daripada 0,7 dan average variance extracted (AVE) lebih besar daripada 0,5 (Chin, 1995). Tiga variabel yang diuji adalah budaya etis (BE), sifat Maceavellian (SM), dan Keputusan Etis. Hasil pengujian menunjukan skor outer loading lebih besar daripada 0,7 pada tiga variable. Hasil ini mengindikasikan seluruh pernyataan dalan kuesioner valid. Hasil skor outer loading dikukung oleh average variance extracted (AVE) yang lebih besar dari 0,5. Nilai AVE masing-masing variable disajikan pada Tabel 4.

PLS menguji validitas diskriminasi dengan Cross loading. Rule of thumb yang digunakan adalah skor cross loading dalam satu variabel lebih besar daripada 0,7 (Chin, 1995). Hasil pengujian menunjukan skor cross loading lebih besar daripada 0,7 pada lima pernyataan variable budaya etis (BE), Sebaliknya, lima pernyataan budaya etis memiliki skor cross loading yang lebih rendah daripada 0,7 pada veriabel SM dan KE. Hasil ini menunjukan lima pernyataan budaya etis valid.

Tabel 3. Hasil Pengujian Validitas Konvergen dengan Outer Loading

\begin{tabular}{llll}
\hline & BE & SM & KE \\
\hline BE1 & 0,798 & \\
BE2 & 0,884 & \\
BE3 & 0,882 & \\
BE4 & 0,731 & \\
BE5 & 0,815 & \\
\end{tabular}




\begin{tabular}{|c|c|c|}
\hline SM1 & 0,724 & \\
\hline SM2 & 0,767 & \\
\hline SM3 & 0,810 & \\
\hline SM4 & 0,740 & \\
\hline SM5 & 0,791 & \\
\hline SM6 & 0,787 & \\
\hline SM7 & 0,720 & \\
\hline SM8 & 0,770 & \\
\hline SM9 & 0,757 & \\
\hline SM10 & 0,818 & \\
\hline SM11 & 0,784 & \\
\hline SM12 & 0,749 & \\
\hline KE1 & & 0,870 \\
\hline KE2 & & 0,866 \\
\hline
\end{tabular}

Sumber: Data diolah, 2017

Hasil pengujian variable SM dan KE menunjukan semua pernyataan variable SM dan KE adalah valid. Nilai cross loading pernyataan terkait variabel SM dan KE lebih besar daripada 0,7 dengan terkait. Sebaliknya, skor cross loading masing-masing pernyataan dengan veriabel yang tidak berhubungan lebih rendah dari 0,7. Hasil pengujian validitas diskriminan disajikan pada Tabel 5.

Tabel 4. Hasil Pengujian Validitas Konvergen dengan AVE

\begin{tabular}{lcccc}
\hline \multicolumn{1}{c}{ Variabel } & $\begin{array}{c}\text { Cronbach's } \\
\text { Alfa }\end{array}$ & rho_A & $\begin{array}{c}\text { Composite } \\
\text { Reliability }\end{array}$ & AVE \\
\hline Budaya Etis & 0,880 & 0,885 & 0,913 & 0,679 \\
Keputusan Etis & 0,673 & 0,673 & 0,859 & 0,753 \\
Sifat Machiavelian & 0,938 & 0,948 & 0,945 & 0,591
\end{tabular}

Sumber: Data diolah, 2017

Uji reliabilitas di dalam PLS menggunakan dua metode, yaitu Cronbach's alpa dan composite reliability. Cronbach's alpa mengukur batas bawah nilai reliabilitas satu kontruk, sedangkan composite reliability mengukur nilai 
sesungguhnya reliabilitas satu kontruk (Chin, 1995). Nilai Cronbach's alpa dan composite reliability minimal adalah 0,7 (Hair et al., 2008). Hasil pengujian reliabilitas menunjukan nilai Cronbach's alpa dan composite reliability lebih besar daripada 0,7, sehingga disimpulkan semua variabel reliabel.

Tabel 5. Hasil Pengujian Validitas Diskriminan dengan Cross Loading

\begin{tabular}{|c|c|c|c|}
\hline & $\overline{B E}$ & SM & KE \\
\hline$\overline{\mathrm{BE} 1}$ & 0,798 & 0,699 & $-0,569$ \\
\hline BE2 & 0,884 & 0,681 & $-0,688$ \\
\hline BE3 & 0,882 & 0,679 & $-0,606$ \\
\hline BE4 & 0,731 & 0,671 & $-0,596$ \\
\hline BE5 & 0,815 & 0,679 & $-0,596$ \\
\hline SM1 & $-0,457$ & 0,724 & $-0,398$ \\
\hline SM2 & $-0,535$ & 0,767 & $-0,576$ \\
\hline SM3 & $-0,581$ & 0,810 & $-0,560$ \\
\hline SM4 & $-0,491$ & 0,740 & $-0,527$ \\
\hline SM5 & $-0,479$ & 0,791 & $-0,503$ \\
\hline SM6 & $-0,502$ & 0,787 & $-0,478$ \\
\hline SM7 & $-0,613$ & 0,720 & $-0,532$ \\
\hline SM8 & $-0,590$ & 0,770 & $-0,530$ \\
\hline SM9 & $-0,589$ & 0,757 & $-0,530$ \\
\hline SM10 & $-0,612$ & 0,818 & $-0,649$ \\
\hline SM11 & $-0,610$ & 0,784 & $-0,670$ \\
\hline SM12 & $-0,656$ & 0,749 & $-0,666$ \\
\hline KE1 & 0,811 & $-0,613$ & 0,870 \\
\hline KE2 & 0,756 & $-0,649$ & 0,866 \\
\hline
\end{tabular}

Sumber: Data diolah, 2017

Model struktural dalam PLS dievaluasi dengan menggunakan koefisien determinasi $\left(\mathrm{R}^{2}\right)$ untuk konstruk dependen, nilai koefisien jalur (path) atau nilai 
statistik $t$ untuk setup jalur. Nilai $\mathrm{R}^{2}$ mengukur tingkat variasi perubahan variabel terhadap variabel dependen. Semakin tinggi nilai $\mathrm{R}^{2}$, berarti semakin baik model prediksi dari model penelitian yang ajukan.

Validitas model diukur menggunakan koefisien determinasi total $\left(\mathrm{R}^{2} \mathrm{~m}\right)$. Nilai koefisien determinasi total $\left(\mathrm{R}^{2}\right.$ total $)$ sebesar 0,834 artinya informasi yang terkandung dalam data 83,4\% dapat dijelaskan oleh model analisis hubungan antar variabel seperti yang tergambar pada Gambar 1, sedangkan sisanya 16,6\% oleh faktor lainnya yang tidak diikutsertakan dalam penelitian ini.

Nilai koefisien jalur atau inner model menunjukan tingkat signifikansi dalam pengujian hipotesis. Hasil analisis koefisien jalur disajikan pada Gambar 1, Gambar 2, dan Tabel 6.

Tabel 6 menunjukan hasil pengujian hipotesis. Hipotesis pertama penelitian (H1) diterima. Budaya etis terbukti berpengaruh positif pada keputusan etis konsultan pajak di Kota Denpasar pada signifikansi 0,05. Hasil pengujian menunjukan koefisien jalur sebesar 0,735, nilai staistik t sebesar 10,190 dan $p$ value sebesar 0,000 .

Gambar 1. Model Algoritma PLS

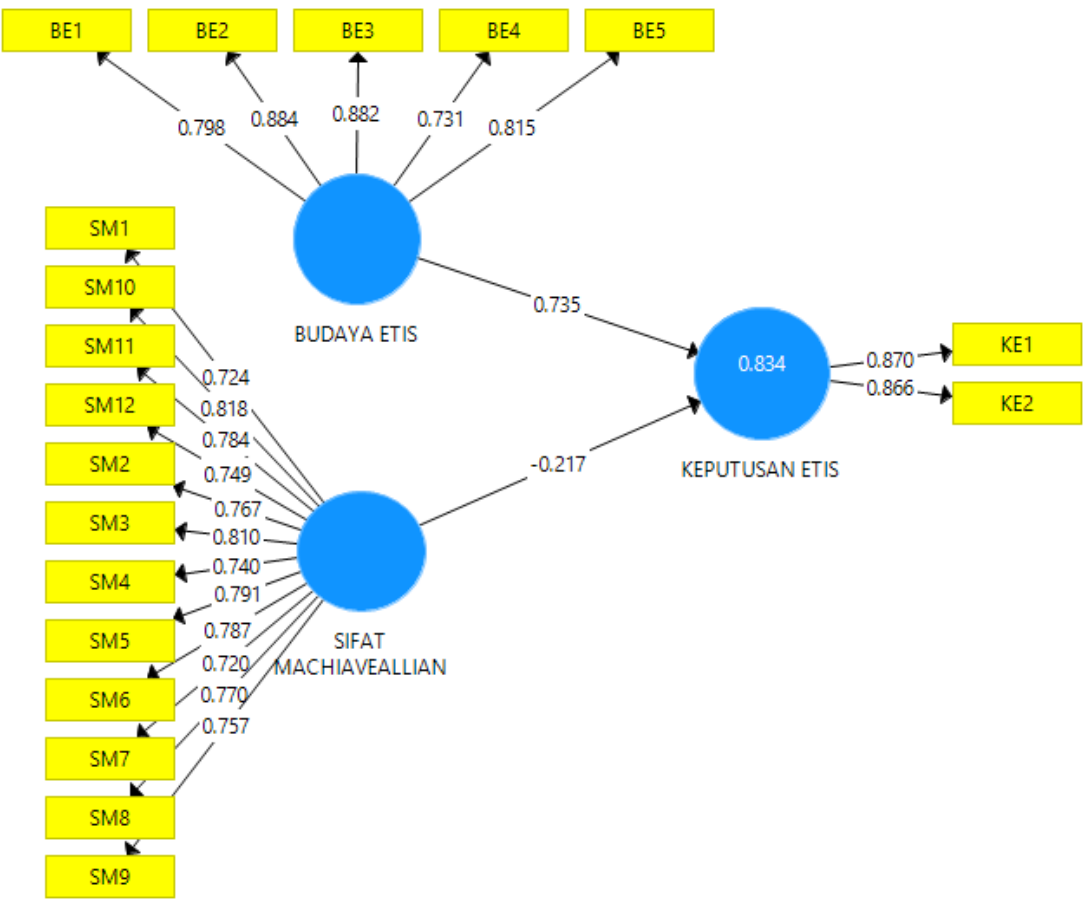


Pengaruh sifat macheavellian terhadap keputusan etis konsultan pajak di Kota Denpasar ditunjukan oleh koefisien jalur sebesar $-0,217$, nilai staistik t sebesar 2,870 terhadap dan $p$ value sebesar 0,004. Sifat macheavellian terbukti berpengaruh negatif terhadap keputusan etis konsultan pajak di Kota Denpasar.

Penelitian ini membuktikan sifat Machiavellian berpengaruh negatif terhadap pembuatan keputusan etis konsultan pajak di Kota Denpasar. Sifat Machiavellian konsultan pajak menjadi proksi perilaku moral yang mempengaruhi perilaku pembuatan keputusan etis, sehingga diekspektasikan bahwa individu dengan sifat Machiavelian tinggi akan lebih mungkin melakukan tindakan yang tidak etis dibandingkan individu dengan sifat Machiavellian rendah. Hasil penelitian ini mendukung penelitian Christie dan Geis (1970) seperti dikutip oleh Purnamasari dan Chrismastuti (2006) menyatakan bahwa Machiavellian merupakan sebuah kepribadian yang antisosial, tidak memperhatikan moralitas konvensional dan mempunyai komitmen ideologis yang rendah. Individu yang memiliki kepribadian Machiavellian yang tinggi melakukan apapun yang diperlukan untuk mencapai tujuannya. Sifat Macheavellian menunjukan sifat seseorang yang cenderung menggunakan taktik manipulatif dan kurang peduli terhadap moral akan terlibat dalam tindakan tidak etis dalam berbagai situasi Shafer dan Simmons (2006). Penelitian lain yang didukung oleh penelitian adalah Singhapakdi (1991) yang menemukan seorang inidividu yang memiliki nilai Machiavellian tinggi cenderung memiliki norma etika yang lebih rendah. Penelitian lain yang dikukung oleh penelitian ini, antara lain Trevino et al. (1985) dalam Purnamasari (2006), Richmond (2001), Pan dan Sparks (2011), Chrismastuti dan Purnamasari (2004), Tjongari dan Widuri (2014), Adriana et al. (2015), Kusuma et al. (2016) dan Ariestanti et al. (2016) yang menyatakan bahwa skala Machiavellian mempengaruhi perilaku pembuatan keputusan etis. Hal ini mengindikasikan bahwa individu dengan sifat Machiavellian tinggi akan lebih mungkin melakukan tindakan tidak etis dibandingkan dengan individu dengan sifat Machiavellian rendah. 


\section{Gambar 2. Hasil analisis PLS dengan Bootstraping}

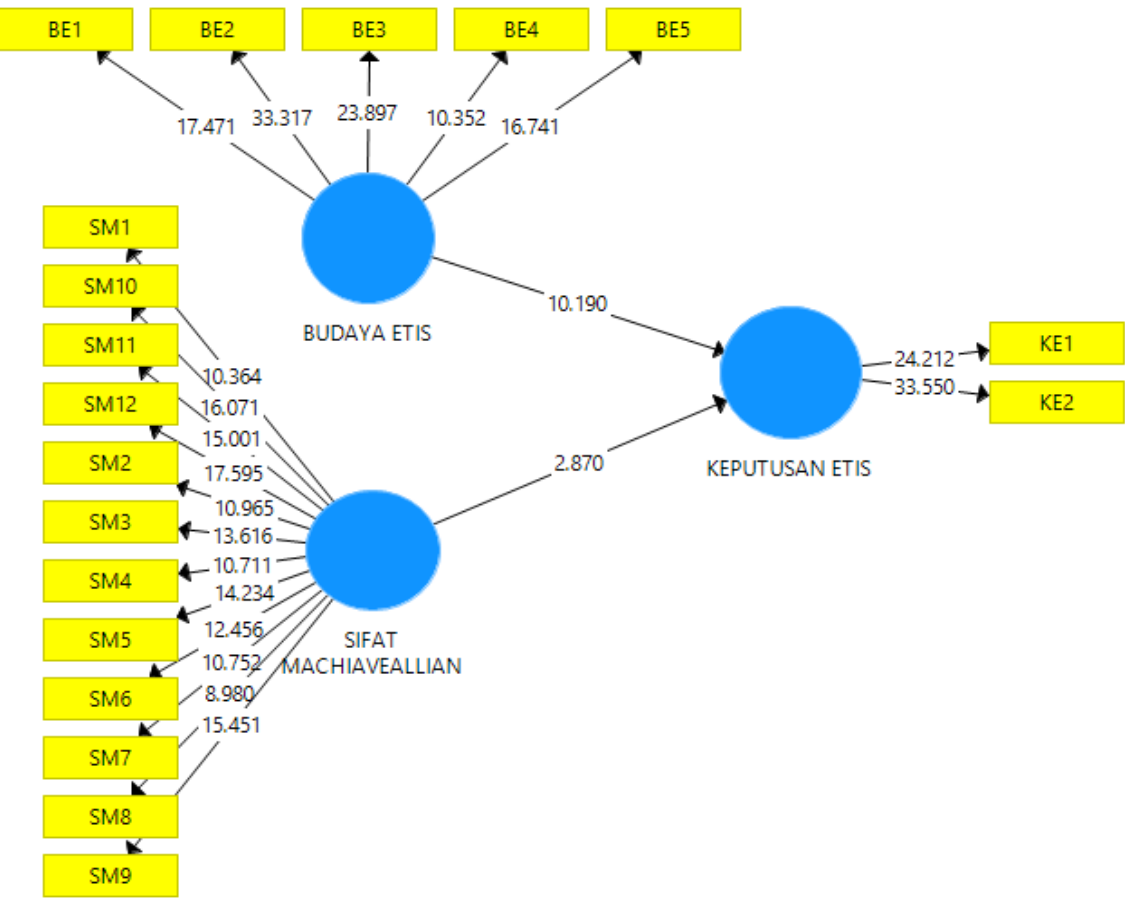

Hasil penelitian ini menemukan pengaruh budaya etis terhadap keputusan etis konsultan pajak di Kota Denpasar. Hasil penelitian mendukung Douglas et al. (2001), Vitell (2006), Noviriantini et al. (2015), Falah (2007), Sutiarsih et al., (2014), dan Marina et al., (2015). Douglas et al. (2001) menyatakan budaya merupakan system nilai yang bersifat umum. Penelitian Douglas et al. (2001) menemukan pengaruh antara budaya etis organisasi pada pertimbangan etis auditor. Penelitian yang dilakukan Vitell (2006) menunjukan bahwa budaya etis organisasi mempunyai pengaruh pada pertimbangan etis. Noviriantini et al. (2015) menemukan budaya etis organisasi berpengaruh negatif terhadap kecenderungan kecurangan (fraud). Budaya etis organisasi terbukti berpengaruh pada sensifitas etis auditor (Falah, 2007; Sutiarsih et al., 2014; Marina et al., 2015.

Tabel 6. Hasil Pengujian Koefisien Jalur

\begin{tabular}{lccc}
\hline & $\begin{array}{c}\text { deviasi } \\
\text { standar }\end{array}$ & t statistik & $p$ value \\
\hline Budaya Etis $\rightarrow$ Keputusan Etis & 0,072 & 10,190 & 0,000 \\
Sifat Machiavellian $\rightarrow$ Keputusan Etis & 0,076 & 2,870 & 0,004 \\
\hline
\end{tabular}

Sumber: Data diolah, 2017. 


\section{SIMPULAN}

Profesi konsultan pajak menghadapi dilemma etis dalam pengambilan keputusan. Keputusan etis konsultan pajak di Bali dipengaruhi dua faktor utama, yaitu karakter moral individu dan budaya etis pada organisasi di mana konsultan pajak bekerja. Faktor-faktor karakteristik individu yang digunakan dalam penelitian ini adalah sifat macheavellian.

Hasil penelitian menemukan sifat macheavellian yang dimiliki oleh konsultan pajak dan budayana etis yang dikembangkan oleh kantor konsultan pajak berdampak pada keputusan etis. Semakin kuat sifat machevellian yang dimiliki oleh seorang konsultan pajak, maka keputusan perpajakan yang diambil akan tidak etis. Budaya etis yang dikembangkan oleh pimpinan kantor konsultan pajak akan meningkatkan keputusan etis konsultan pajak.

Hasil penelitian ini dapat menjadi pedoman pimpinan kantor konsultan pajak dalam meningkatan keputusan etis konultan pajak. Pimpinan konsultan pajak agar memperhatikan sifat macheavellian yang dimiliki oleh staf ketika menerima lamaran pekerjaan. Konsultan pajak yang memiliki sifat macheavellian yang lemah diharapkan meningkatkan pengambilan ketupusan etis. Pimpinan Kantor konsultan pajak disarankan mengembangkan budaya etis di organisasi yang dipimpin untuk meningkatkan keputusan etis para konsultan pajak.

\section{PUSTAKA ACUAN}

Adriana, P., Rosidi, Dan Baridwan, Z. 2015. Determinan Pembuatan Keputusan Etis Konsultan Pajak. Tesis. Program Pascasarjana Fakultas Ekonomi dan Bisnis Universitas Brawijaya.

Alchian, A., \&Demsetz., H. 1972. Production, information costs, and Economic organization. American Economic Review. Vol. 52: 777-795.

Apriliawati, N.K. dan Suardana, K.A. 2016. Budaya Etis Organisasi Sebagai Variabel Pemoderasi Pengaruh Orientasi Etis Pada Pertimbangan Etis Auditor. EJournal Akuntansi Universitas Udayana. Vol.17, No2: 1226-1253. 
Arestanti, M.A., Herawati, N., dan Rahmawati, E. 2016. Faktor-Faktor Internal Individual dalam Pembuatan Keputusan Etis: Studi pada Konsultan Pajak di Kota Surabaya. Jurnal Akuntansi dan Investasi. Vol. 17, No. 2: 104-117.

Chaplin. 1995. Kamus Lengkap Psikologi. Jakarta: PT. Raga Grafindo Persada.

Christie, R \& Geis, F. 1970. Studies In Machiavellianism. NY:Academic Press.

Douglas P. C, Ronald A. Davidson dan B. N Shwartz. 2001. The Effect of Organizational Cultuter and Ethical Orientation on Accountants Ethical Judgements. Journal of Business Ethics. No. 34: 101-121.

Erard, B. 1993. Taxation with representation: An analysis of the role of tax practitioners tax compliance. Journal of Public Economics. Vol. 52, No.2: 163-197.

Falah, S. 2007. "Pengaruh Budaya Etis Organisasi Dan Orientasi Etika Terhadap Sensitivitas Etika (Studi Empiris Tentang Pemeriksa Internal Bawasda)". Makalah disampaikan dalam Seminar Nasional Akuntansi X, Universitas Hasanudin Makasar, 26-28 Juli 2007.

Ferrel dan Gresham. 1985. A Contingency Framework for Understanding Ethical Decision Making in Marketing. Journal of Marketing. Vol. 49: 87-96.

Fogarty, T.J. 1992. Organizational Socialization in Accounting Firm: A Theoretical Framework and Agenda for Future Research. Accounting, Organizations and Society. No.17 (February):129 -149.

Gargalas, V. dan Lehman, H. 2010. Employing a Tax Practitioner: A Different Perpective. Journal of Business \& Economics Research. Vol. 8. No.2.

Griffin, Rizky W., dan R. J Ebert. 1998. Business. Fourth Edition. Englewood. Clift: Prentice Hall Inc.

Hunt, S. D dan Vitell. 1986. A General Theory of Marketing Ethics. Journal of Macromarketing. No. 6 (Spring): 5 - 16.

IKPI, Komisi Kode Etik. 2009. AD ART Kode Etik Ikatan Konsultan Pajak Indonesia. Batam: Komisi Kode Etik.

Jones, Thomas. M. 1991. Ethical Decision making by Individuals in Organizations: An Issue-Contingent Model. Academy Management Review. April: 365 - 395. 
Kusuma, T.H., Utami, H.N., dan Ruhana, I. 2016. Pengaruh Persepsi Peran Etika Dan Tanggung Jawab Sosial, Sifat Machiavellian, Dan Preferensi Risiko Terhadap Pengambilan Keputusan Etis (Studi Pada Konsultan Pajak Di Kota Malang). Jurnal Perpajakan (JEJAK). Vol. 10, No. 1: 1-10.

Martina, M.B., Werastuti, D.M., dan Sujana, E. 2015. Pengaruh Budaya Etis Organisasi, Orientasi Etika, Pengalaman, Dan Profesionalisme Terhadap Sensitivitas Etika Kegiatan Audit Yang Dilaksanakan Inspektorat Pemerintah Kabupaten Buleleng. E-Journal S1 Ak Universitas Pendidikan Ganesha Jurusan Akuntansi S1, Volume 3 No. 1.

Ouchi, W.G. 1980. Markets, Bureaucrarcies, and Clans. Administrative Science Quarterly, 25 (March): 129 - 141.

Pan, Yue dan Sparks, John. 2011. Predictors, consequence, and measurement of ethical judgments: Review and meta-analysis. Journal of Business Research 65: 84-91.

Pemerintah Republik Indonesia. Undang-Undang Nomor 28 Tahun 2007 tentang Ketentuan Umum Dan Tata Cara Perpajakan.

Ponemon, L. A. 1990. Ethical Judgements in Accounting: A Cognitivedevelopmental Perspective. Critical Perspectives on Accounting 1: 191 - 215.

Purnamasari, Vena dan Chrismastuti, Agnes. 2006. Dampak Reinforcement Contingency terhadap Hubungan Sifat Machiavellian dan Perkembangan Moral. Diseminarkan pada Simposium Nasional Akuntansi 9 Padang.

Purnamasari, Vena. 2006. Sifat Machiavellian dan Pertimbangan etis: Anteseden Independensi dan Perilaku Etis Auditor. Diseminarkan pada Simposium Nasional Akuntansi 9 Padang.

Richmond, K. A. 2001. Ethical reasoning, Machiavellian behavior, and gender: The impact on accounting students' ethical decision making. Doctoral dissertation. Virginia Polytechnic Institute and State University.

Robbin, S.P. 1996. Organizational Behavioral. Seventh Edition. Englewood Cliff: Prentice Hall, Inc. 
Schein, EH. 1985. Organizational Culture and Leadership. Jossey-Bass, San Fransisco.

Shafer, William dan Simmons, Richard. 2006. Social Responsibility, Machiavellianism And Tax Avoidance: A Study of Hong Kong Tax Professionals. Department of Business Law \& Taxation Corporate Law and Accountability Research Group Working Paper No. 5 Monash University Social Science Research Network electronic library.

Shafer, William E dan Richard S. Simmons. 2008. Social Responsibility, Machiavellianism, and Tax Avoidance: A Study of Hong Kong Tax Professionals. Accounting, Auditing, and Accountability Journal, Vol. 21, No. 5: 695-720.

Singhapakdi. 1999. Perceived Importance of Ethics and Ethical Decisions in Marketing. Journal of Business Research. Vol. 45: 89-99.

Sutiarsih, G.A., Herawati, N.T., dan Sinarwati, N.K. 2014. Pengaruh Budaya Etis Organisasi, Idealisme, Dan Relativisme Terhadap Sensitivitas Etika Auditor (Studi pada Aparatur Inspektorat Pemerintah Kabupaten Buleleng). EJournal S1 Ak Universitas Pendidikan Ganesha Jurusan Akuntansi Program S1. Vol. 2 No. 1.

Tjongari, F.V. dan Widuri, R. 2014. Analisis Faktor-Faktor Individual Yang Berpengaruh Terhadap Pengambilan Keputusan Etis Konsultan Pajak (Survey Pada Konsultan Pajak Di Jawa Timur). Tax \& Accounting Review. Vol 4, No 2: 1-7.

Trevino, L. K., \& Youngblood, S. A. 1990. Bad apples in bad barrels: A causal analysis of ethical decision-making behavior. Journal of Applied psychology, 75(4): 378.

Vitell, S.J., and E.R. Hidalgo. 2006. The Impact of Corporate Ethical Values Ana Enforcement of Ethical Codes on The Perceived Importance of Ethics $\mathrm{Ni}$ Business: A Comparison of U.S and Spanish Managers. Journal of Business Ethics, 64: 31-43. 